\title{
Atenção ao parto de mulheres estrangeiras em uma maternidade pública de São Paulo
}

\section{Foreign women giving birth at a public maternity ward in the city of São Paulo}

\author{
Cláudia Medeiros de Castro* \\ Régia Cristina Oliveira** \\ Mayara Cristina Silva Custódio***
}

\begin{abstract}
Resumo: Realizamos pesquisa que teve como objetivo geral conhecer os sentidos da atenção ao parto, construídos por profissionais de saúde que atenderam mulheres estrangeiras em um hospital maternidade do município de São Paulo. Acessamos 1248 Declarações de Nascidos Vivos de filhos de estrangeiras produzidas em 2012 e realizamos entrevistas com 10 profissionais de saúde. Os resultados indicam que no período estudado $20 \%$ dos partos foram de estrangeiras, sendo $85 \%$ bolivianas. Temas que surgiram nas entrevistas: as contradições do país onde não há discriminação; a língua como aproximação e barreira; a submissão das mulheres bolivianas e as diferenças culturais no parto.
\end{abstract}

Palavras-chave: Imigração estrangeira. Práticas discursivas. Atenção ao parto.

Abstract: A research was carried out on parturition in order to understand it better. The research aims to understand the meanings/interpretations of childbirth for the health professionals who attended foreign women at a maternity ward in the municipality of São Paulo. Documents which informed about live births from foreign mothers were analyzed and interviews were also carried out with health professionals. The outcomes for the studied period indicate that $20 \%$ of childbirths were from foreign women, $85 \%$ of which were Bolivian. The following issues were discussed in the interviews: the

* Doutora em Ciências pelo PPG da Coordenadoria de Controle de Doenças da Secretaria da Saúde do estado de São Paulo (SES-SP, São Paulo, SP, Brasil) e docente do Curso de Obstetrícia da Escola de Artes, Ciências e Humanidades da Universidade de São Paulo em São Paulo, SP<claudia.medeiros@usp.br>.

**Doutora em Sociologia pela Universidade de São Paulo (USP, São Paulo, SP, Brasil) e docente do Curso de Obstetrícia e do PPG em Estudos Culturais, ambos da Escola de Artes, Ciências e Humanidades da Universidade de São Paulo<re.oliveira@usp.br>.

***Graduada em Obstetrícia pela Escola de Artes, Ciências e Humanidades da Universidade de São Paulo<mayaracustodiio@gmail.com>. 
contradictions of the country where there is no discrimination; language barrier and language as a way of approaching; "submission" from Bolivian women and cultural differences during childbirth.

Keywords: Immigration. Obstetric care. Discursive practices. Childbirth.

\section{Introdução}

Nas últimas décadas o Brasil tem ocupado importante lugar na rota da migração internacional do Cone Sul, com especial destaque para os imigrantes bolivianos (Baeninger (2012). Algumas décadas passadas, a migração boliviana tinha como característica a mobilidade dirigida às regiões de fronteira. Posteriormente, dirigiu-se para a região ocupada pelo município de São Paulo e municípios que compõem a região metropolitana da Grande São Paulo. Análises indicam que o fenômeno ocorre há cerca de seis décadas, pois já nos anos 1950 há registro da vinda de estudantes para o Brasil. Nos anos 1980, jovens bolivianos chegaram ao país para trabalhar principalmente no setor têxtil, período em que se observou o crescimento da presença feminina, que forma parte da mão de obra usada nas oficinas de costura (Silva, 2012). Em busca de uma vida melhor, homens e mulheres são submetidos a condições precárias de trabalho, com jornadas extensas, moradias insalubres e sem direitos trabalhistas, uma vez que boa parte dos imigrantes são indocumentados (Silva, 2012, Waldman, 2011; Illes et al., 2008). Informações dos censos demográficos indicam o crescimento da presença dos bolivianos no município: em 1980, eram 3.213; em 1990, eram 4.525 e 2000 eram 7.722. Como muitos imigrantes são indocumentados, estima-se que a colônia boliviana seja bem maior. Muitos dso que por aqui chegam têm origem nas chamadas terras altas da Bolívia; são de origem Quíchua ou Aimara, grupos andinos que trazem consigo elementos culturais do antigo Império Inca (Shouchaud e Baeninger, 2008).

No que diz respeito aos aspectos culturais relacionados à saúde, para os povos andinos que se organizam em sociedades comunitárias e compartilham uma cosmovisão do mundo onde o corpo é pensado como existindo em relação com os deuses e o universo e a saúde, afirma Rodríguez (2008), a saúde não se reduz ao corpo, sendo então relativa a um "conjunto de fatores sociais, afetivos, ambientais e espirituais que determinam a harmonia interna e externa, individual e comunitária". A autora, em estudo sobre os determinantes culturais do parto, assinala que as mulheres indígenas de origem andina que vão ter seus filhos nos hospitais esperam ter acesso a um serviço que ofereça atenção de boa qualidade, mas também desejam que no parto algumas práticas 
sejam respeitadas, como parir na posição vertical, de cócoras ou ajoelhadas; algumas desejam que a placenta seja entregue a elas para que a mesma possa ser enterrada, prática comum em alguns grupos. Pesquisa sobre assistência obstétrica em países das Américas (Souza et al., 2007) mostrou que na Bolívia $46 \%$ dos partos foram domiciliares e uma taxa de $13,7 \%$ de cesáreas no país. Em algumas localidades, o acesso aos serviços de saúde para assistência ao parto é baixo. Pesquisa realizada por Kelsey e Brett (2008) indica entre os principais motivos para isso, que as mulheres têm medo ou vergonha de receber assistência nesses locais; consideram ruim a qualidade do serviço, apontando dificuldades linguísticas dadas pela incompreensão dos profissionais de saúde do idioma indígena; outros entrevistados mencionaram razões relacionadas à diferença de classe, cultura e etnia, para não serem bem tratadas no serviço; algumas alegam, ainda, as barreiras geográficas como dificuldade para acessar os serviços.

Quanto à atenção à saúde no município de São Paulo, estudo realizado com mulheres bolivianas frequentadoras do Centro de Apoio ao Migrante mostrou que $89 \%$ acessou os serviços de saúde; muitas delas mencionaram problemas de comunicação; percepção de atitude negativa por parte da equipe de saúde por não falarem português, com relatos como "não falam fácil, te olham feio, gritam, empurram" (Waldmann 2011, p. 100). Elas consideraram ainda que há mais demora para atender bolivianos que brasileiros. Com relação à atenção obstétrica, no ano de 2013 ocorreram 2.822 partos de nascidos vivos de mães bolivianas, que corresponde a 1,63\% do partos, das quais 50\% realizaram sete ou mais consultas pré-natal (Prefeitura de São Paulo, 2014).

Considerando a necessidade da realização de mais estudos que possam contribuir para o conhecimento sobre a atenção à saúde dos imigrantes no Sistema Único de Saúde, bem como a necessidade de conhecer o modo como os profissionais de saúde lidam com o fenômeno da migração no seu cotidiano de trabalho, realizamos pesquisa ${ }^{1}$ que teve como objetivo conhecer os sentidos da atenção ao parto construídos por profissionais de saúde que atendem mulheres estrangeiras em um hospital maternidade do município de São Paulo, dentre elas, sobressaindo-se em número, mulheres bolivianas. Para tanto, são apresentadas e discutidas falas de profissionais de saúde que atendem as mulheres na referida instituição.

\footnotetext{
${ }^{1}$ Neste artigo apresentamos parte da pesquisa "Nos caminhos do parto culturalmente adequado: os sentidos da atenção ao parto de mulheres estrangeiras em uma maternidade pública de São Paulo", que incluiu atividade de Iniciação Científica.
} 
Para a apreensão analítica do termo estrangeiro, apoiamo-nos em Simmel (2005), para quem o estrangeiro não é aquele que "vem hoje e amanhã se vai", mas aquele que "vem hoje e amanhã pode permanecer". Esta noção parece-nos pertinente para pensar as bolivianas que têm filhos no país e que, em função disso, muitas vezes aqui permanecem, ocupando ou buscando ocupar os espaços sociais, como os serviços de saúde, não sem dificuldades e, ao mesmo tempo, fazendo-o de um modo particular. Como desenvolve Simmel (2005, p. 265), o estrangeiro é o indivíduo que "não pertence imediatamente ao espaço". Ainda que seja um elemento do grupo, é também "um elemento do qual a posição imanente e de membro compreendem, ao mesmo tempo, um exterior e um contrário". Isso pode ser percebido no caso das bolivianas que, ao mesmo tempo em que fazem parte do grupo de parturientes atendidas pelo hospital maternidade em estudo, compreendem uma espécie de contrário, posto nas diferenças, por exemplo, dos costumes particulares em relação às posições de parto e às relações com seus cônjuges.

\section{Considerações teórico-metodológicas}

$\mathrm{Na}$ condução da pesquisa, adotamos a perspectiva construcionista social, segundo a qual o conhecimento é visto como algo que é construído pelas pessoas em seu cotidiano, quando por meio das práticas discursivas posicionam-se e buscam dar sentido ao mundo que as cerca (Cabruja et al., 2000; Spink, 1999). Metodologicamente, tendo em vista o caráter interpretativo da análise, foi utilizada a abordagem qualitativa. A pesquisa foi submetida ao comitê de ética em pesquisa da universidade e do hospital maternidade onde foi realizado o campo. Como técnicas de pesquisa, realizamos coleta de dados contidos em 1.248 Declarações de Nascidos Vivos (DNV), produzidas de outubro a dezembro de 2012 e coletadas em dezembro de 2012 e janeiro de 2013, para conhecer a demanda de atendimento de estrangeiras na instituição e realizamos entrevistas semi-estruturadas com 10 profissionais de saúde que atenderam mulheres estrangeiras. A análise das entrevistas foi realizada tendo como suporte teórico metodológico a perspectiva de Spink (1999).

Os profissionais de saúde foram contatados e convidados a participar da pesquisa nas salas destinadas a atividades administrativas e no Centro de Parto Normal. Acreditamos que o aceite foi facilitado pelo fato da pesquisadora ter trabalhado na instituição em anos anteriores, ainda que tenha conhecido alguns profissionais apenas quando da realização da pesquisa. Procurou-se incluir profissões que compõem a equipe de saúde que atende as parturientes e mulheres no pós-parto. As entrevistas semi-estruturadas, que foram gravadas e posteriormente transcritas, tiveram por objetivo conhecer quais os sentidos 
construídos por profissionais envolvidos no cenário da atenção ao parto, quando do oferecimento da assistência às estrangeiras. O maior tempo de trabalho na instituição foi 19 anos e o menor dois anos, o tempo médio de trabalho na instituição foi 13 anos. Duas entrevistadas eram descendentes de estrangeiros (japonês e árabe) e uma entrevistada era estrangeira nacionalizada brasileira. Quanto aos profissionais, foram entrevistados: duas assistentes sociais; três enfermeiras; duas médicas e um médico; duas psicólogas. Diante do vasto material, procedemos a uma organização temática onde destacamos os seguintes temas para a discussão deste artigo: aspectos sociais da imigração estrangeira; a língua/idioma como aproximação e barreira; a "submissão" das mulheres bolivianas e as diferenças culturais no parto.

Inicialmente, apresentaremos a instituição onde desenvolvemos a pesquisa.

\section{Ecos da imigração no cotidiano institucional}

O Hospital Maternidade estudado é uma unidade que integra o Sistema Único de Saúde e está localizado na Zona Leste do Município de São Paulo, em região próxima ao bairro do Brás, que é conhecido pela fabricação e comércio de artigos têxteis. Esse hospital oferece atenção obstétrica, ginecológica e neonatal. A instituição tem tradição na formação de profissionais de saúde, com a manutenção de programa de residência médica em ginecologia e obstetrícia, neonatologia e oferecimento de campo de estágio para graduandos de medicina, obstetrícia e enfermagem, além de outras atividades voltadas para a formação em saúde. O hospital desenvolve ações voltadas para a humanização do atendimento, como o Programa Mãe Canguru, destinado aos bebês prematuros, que ficam em contato pele-a-pele com a mãe até terem condições de alta hospitalar e incentiva o aleitamento materno. Nos anos 2000, recebeu o título Hospital Amigo da Criança e o prêmio Maternidade Segura. O local conta com um programa de voluntariado e Comissão de Humanização. Com relação à atenção obstétrica, o hospital possui um Centro Obstétrico e também um Centro de Parto Normal, onde as mulheres permanecem no mesmo quarto durante o trabalho de parto, o parto e após nascimento do bebê, assistidas por enfermeiras obstetras. Posteriormente, mãe e bebê são transferidos para o Alojamento Conjunto. Em 2012, o hospital realizou 5.728 partos, sendo 3.851 partos normais e 1.877 cesáreas. As informações das 1.248 DNV que coletamos permitiram identificar $251 \mathrm{DNV}$ de filhos de mulheres estrangeiras de várias nacionalidades (boliviana, chinesa, paraguaia, peruana, nigeriana, angolana, argentina, haitiana e sul-africana), o que corresponde a $20 \%$ dos partos de nascidos vivos da Maternidade no período estudado. As bolivianas corresponderam a $85,3 \%$ das estrangeiras. 
Ao caminhar pelas dependências e arredores do hospital, é comum encontrar mulheres imigrantes, grávidas ou carregando seus bebês. Conforme relato de profissionais entrevistados, a grande procura de bolivianas pelo hospital levou a instituição a realizar algumas atividades voltadas para os profissionais em parceria com o Consulado da Bolívia e a Pastoral do Imigrante. Uma dessas atividades foi a realização de uma feira, onde foram oferecidas as seguintes atividades: palestras sobre a Bolívia; comidas típicas e apresentação de danças típicas. Foi oferecido curso de introdução ao espanhol e aimara. Nos corredores e enfermarias da instituição não é raro encontrar mensagens curtas/ avisos em português e espanhol destinadas às usuárias e acompanhantes.

\section{As contradições do país onde não há discriminação}

“A presença de estrangeiros é bem complicada. A gente vê até no Pronto Atendimento a pobreza em que essa população vive. É um regime de quase escravidão que elas vivem aqui no Brasil, então, em relação a isso é bem complicado [...]", avalia Lina, ${ }^{2}$ uma das médicas entrevistadas.

Ao ser questionada sobre o que, para ela, revela a pobreza mencionada, diz: "em relação a, a tudo, entendeu? Na vestimenta, no jeito que, é, são pacientes mais acabadas, que você sabe que, é... a idade não corresponde com a aparência dela. É, é precária a higiene também".

Os profissionais entrevistados tiveram e têm contato com mulheres estrangeiras em seu cotidiano de trabalho. Tal situação parece levá-los a pensar no fenômeno migração estrangeira para além do hospital onde realizam suas atividades. Como a maioria das estrangeiras atendidas são bolivianas, foi sobre a situação da migração boliviana que se referiram com mais frequência. Buscando explicar os motivos da vinda de estrangeiros para o Brasil, em suas narrativas, alguns reproduziram a ideia de que o Brasil é um país "bonito", onde "não há discriminação". Todavia, outras questões apontadas revelaram tensões e contradições, tanto no atendimento quanto na percepção sobre os estrangeiros no país. Houve, entre alguns profissionais de saúde, a percepção da falta de diretrizes ou políticas públicas voltadas para a população estrangeira, o que é constatado na literatura sobre o tema (Waldman, 2011). Também houve uma associação entre migração e pobreza, especialmente no que diz respeito às bolivianas que, de fato, em sua maioria, trabalham em condições precárias, análogas à escravidão, nas oficinas de costura do setor têxtil da região do bairro do Brás, o que ocorre em outras unidades de saúde localizadas em bairros próximos da região central da cidade (Waldman, 2011; Madi et al., 2009).

\footnotetext{
${ }^{2}$ Os nomes são fictícios para garantir o anonimato dos entrevistados.
} 
De todo modo, ainda que a referência à pobreza das bolivianas seja resultado de uma constatação pelos profissionais do que a literatura sobre o tema afirma, há nas falas uma associação entre pobreza e "falta de higiene", esta percebida dentro dos moldes da noção higienista de corpo, família, classe social, muito presente nos hospitais em geral (Costa, 1979), mesmo naqueles comprometidos com ações e práticas de humanização, como no referido local de estudo.

Torniquist (2003, p. 426), em estudo sobre as experiências de parturientes e as diferenças culturais que se apresentam nas interações com a equipe de saúde, também destaca esse aspecto, ao afirmar que "o peso da herança higienista se faz presente hoje nas rotinas hospitalares e, sobretudo, nas práticas dos profissionais, ainda que articulados com valores de mudança e de humanização". A autora aponta a existência de "heterogeneidades no atendimento", sobretudo na equipe médica, menos permeável "às modificações de tipo humanizador" do que a equipe de enfermagem, tendo em vista a primeira ser dotada de "maior margem de poder e autonomia". Preocupa a autora a desatenção em relação às diferenças socioculturais entre as mulheres que, atrelada à forte herança higienista da medicina, pode minimizar o potencial do parto humanizado.

Fonseca (1992, p. 11) em estudo realizado em uma maternidade pública francesa com a finalidade de analisar problemas de comunicação/ "incompreensão" existentes entre pessoas do hospital e as parturientes que frequentavam o serviço, dentre as quais, mulheres africanas, ressalta, em sua análise, o fato de que para a compreensão desses problemas é necessário a apreensão não apenas das diferenças étnicas entre as pessoas do hospital e as parturientes estrangeiras, mas, principalmente, a apreensão das diferenças de classe e o modo como o olhar para essas diferenças repercute nas relações. Conforme aponta, as "relações interclasses podem ser tão complicadas quanto as relações interétnicas, e com noções pré-concebidas ainda mais sólidas.” Em muitas situações, avalia, a pobreza é associada a desajustamentos; estereótipos sobre "os pobres desajustados" que dificultam ou mesmo impossibilitam a comunicação com a equipe do hospital.

De modo análogo, no presente estudo problemas de comunicação existentes entre os profissionais do hospital e as parturientes bolivianas são dados tanto por diferenças culturais e linguísticas quanto pela relação interclasses, esta, em especial, fundamentada e atualizada, no cotidiano das práticas de atendimento, em noções higienistas sobre pobreza, corpo, maternidade e higiene. 


\section{A instituição e o atendimento de estrangeiras: comunicação, aproximações e barreiras}

"Então, [o preconceito] melhorou bastante né, eu acho que assim perto do que era antigamente porque assim, a gente já viu preconceito na nossa equipe com relação a bolivianos, e justamente uma das intenções nossas de fazer esse evento era para quebrar um pouco", diz a assistente social Rosana.

As entrevistadas relataram iniciativas institucionais que tiveram o intuito de procurar criar melhores condições para o acolhimento das bolivianas e facilitar a comunicação com elas, como a realização de uma feira e um curso de espanhol e aimara, em parceria com o Consulado da Bolívia e a Pastoral do Imigrante. Para Zaíra, assistente social, essa iniciativa teve bom resultado. Ela disse ter aprendido espanhol no curso e que, atualmente, é solicitada por outros profissionais a ajudar na comunicação dos mesmos com as bolivianas. Ao mesmo tempo, parece-nos que as iniciativas individuais relatadas nas entrevistas, como registrar em um caderno palavras e termos usados por estrangeiras também tem grande importância no cotidiano dos atendimentos. Um dos médicos, João menciona este aspecto: "a gente fica dois, três dias acompanhando elas, ai você cria um vínculo, eu tenho um caderninho na minha bolsa que eu perguntava as coisas pra elas, algumas palavras, e assim facilitou muito a comunicação." Outros entrevistados também relataram utilizar aplicativos de tradução via celular, mostrar desenhos das posições do parto, gesticular, chamar alguém da instituição que saiba falar a língua.

Esse esforço real de entender o outro, presente em alguns profissionais, acaba por coexistir com atitudes opostas, pouco preocupadas com a compreensão do outro e pelo outro: "Alguns [profissionais] ainda até se esforçam em se fazer entender né, e de entender, às vezes até já teve casos que eu fui chamada pra fazer a tradução, agora tem outros que não, tipo, dá a orientação e entendeu, entendeu, não entendeu o problema é dela", observa Zaíra. Outra entrevistada, a enfermeira Jeane, que é naturalizada brasileira, reforça a ideia: "Alguns [médicos] ficam bravos porque não sabe falar bem português. Porque sabe, tem que, né? Estrangeiro tem que saber falar português, não assim, sabe, gesto. Às vezes liga na minha casa, já aconteceu de ligar em casa meia-noite, aí tem alguns médicos que não aceitam falar por telefone. Porque eu falei, eu não posso ficar acompanhando o tempo todo, eu também tenho família, tenho minhas coisas pra fazer, né?"

De fato, não é possível que todos os funcionários do hospital, profissionais de saúde e administrativos, saibam falar espanhol, apenas por ter sido oferecido um curso pela instituição, que certamente não foi usufruído por todos. Todavia, 
como mostra a entrevistada, alguns profissionais de saúde limitam-se a passar as orientações, não sendo colocado o esforço da compreensão e do diálogo com a estrangeira. Essa atitude faz manter as barreiras de comunicação, ao mesmo tempo em que enfatiza as diferenças como um marcador do poder "nacionais" sobre os estrangeiros, somado ao poder médico sobre os sujeitos que estão no serviço para serem atendidos.

Apoiamo-nos em Foucault (1979; 2006), que entende o poder não como algo que é possuído por alguém, mas que responde a uma rede de relações complexas que se alia ao saber. O poder, discorre o autor, "funciona e se exerce em rede [...], não se aplica aos indivíduos, passa por eles. [...]”, constituindo os indivíduos. "Efetivamente, aquilo que faz com que um corpo, um gesto, discursos e desejos sejam identificados e constituídos enquanto indivíduos é um dos primeiros efeitos do poder" (1979, p. 183). Nas sociedades ocidentais, destaca o autor, a medicina, lugar central de produção de discurso sobre os corpos, é uma referência fundamental, influenciando, através de seu discurso, diferentes campos da vida, não apenas o da saúde.

Com base nesse poder saber médico, orientações são passadas aos sujeitos, as quais respondem por uma racionalidade, historicamente construída e que impõe uma assimetria entre aquele que detém o saber científico médico e aquele que está ali para ser tratado. Cabe a este, avalia Caponi (2000), a obrigação moral de dizer toda a verdade sobre si, de ser inteligível, não encontrando, todavia, a necessária contrapartida daquele, no referente à inteligibilidade e, mesmo, à não ocultação de toda a "verdade" sobre o "paciente". Isso é ainda mais radicalmente colocado para as estrangeiras bolivianas que buscam os serviços no hospital, que não compreendem bem a língua portuguesa e que estão em situação de subalternidade social, situando-se de modo ainda mais assimétrico na relação de atendimento.

\section{A "submissão" das mulheres bolivianas e os aspectos culturais do parto}

"As mulheres [bolivianas] elas, o que você percebe? Que elas são mais submissas né. Então muitas vezes elas não conseguem dialogar tanto, ou tão bem quanto o homem, né?", avalia a enfermeira Priscila.

Várias entrevistadas usaram os termos "submissa", "submissão" em referência à mulher boliviana. Tal característica, longe de ser considerada como algo ruim, alicerçado na desigualdade de gênero que incide tanto na vida das mulheres brasileiras quanto das estrangeiras, foi considerada por uma entrevistada como algo que facilita a colaboração, ajuda a não ter "problemas" durante o atendimento. Trata-se da valorização da submissão, vista como algo 
"próprio" da boliviana, ao atendimento e prescrições médicas, que então se impõe na definição do cuidado. Submeter-se para ser "bem atendida" e "não criar problema". Como diz Marta, elas "são colaboradoras, as bolivianas principalmente, elas são humildes, elas são bem submissas, então o que você fala ela logo atende, diferente de outras que não atende, que rebate né, e que são rebeldes, elas não. A maioria, 70\%, 80\% elas são bem submissas, e não temos tido problemas não".

Estudo realizado por Fonseca (1992, p. 16) avalia um juízo de valor existente sobre as parturientes de uma maternidade pública francesa, a passividade, mostrando como o mesmo the parece equivocado. Segundo sua análise, para "julgar esta passividade, precisamos primeiro lembrar que estamos lidando com pessoas de classes subalternas acostumadas a "conhecer seu lugar' ante as autoridades institucionais". Quando está diante do médico, a mãe percebe que a postura do profissional assinala a inferioridade dela, para quem o conhecimento hegemônico não é acessível.

Do mesmo modo, a "passividade" da mulher boliviana pode ser pensada nesse mesmo registro das desigualdades ante os saberes biomédicos instituídos e a situação de subalternidade social em que se encontram. Fonseca (1992) acrescenta "que quanto mais alto o profissional está na hierarquia, mais os pacientes lhe parecem passivos."

Outras profissionais revelam a percepção da relação desigual entre homens e mulheres bolivianas, que se manifesta em várias situações observadas no cotidiano de trabalho, como ao homem/companheiro ser delegada a comunicação com a equipe e a escolha do nome da criança. Como diz Rosana “[...] porque é uma cultura mais machista também, né, então o homem domina, você vê que até a escolha do nome é ele quem faz, na maioria das vezes é ele, a mulher não sabe o nome do filho, sempre 'ah eu não sei, ele não me falou ainda, to esperando meu marido' [bolivianas], então, muito é o homem que resolve." Relações de gênero desiguais vividas por imigrantes bolivianas são relatadas também na literatura sobre o tema, exemplificadas por Illes et al. (2008) que informam sobre a prioridade dada ao homem para se documentar e legalizar sua situação no Brasil.

Todavia, estudos com mulheres estrangeiras apontam a necessidade de não generalização quanto à percepção de subordinação nas relações marido e mulher. Como analisa Fonseca (1992, p. 23), ao falar sobre a mulher africana, é "difícil generalizar sobre a subordinação da mulher à autoridade do marido. Não somente o jogo do poder doméstico varia muito de acordo com a etnia como a situação específica do imigrante provoca profundas modificações no comportamento tradicional [...]." 
No que diz respeito à percepção de diferenças culturais no parto, algumas entrevistadas em seus relatos se limitaram a indicar como grande diferença a escolha pelo parto normal, escolha esta que parece ser aceita pela equipe. Como menciona a enfermeira Priscila, que trabalha no hospital há 19 anos, "elas [bolivianas] preferem tá tendo o parto normal, o que as brasileiras já chegam pedindo cesárea, o boliviano não, eles querem ter o parto normal porque eles sabem que aquele momento do stress do pré-parto ele vai passar assim que nascer [...] e eu acho que essa é a diferença mais gritante".

Como destaca Fonseca (1992, p. 25) ao discorrer sobre a percepção e comportamento dos profissionais na maternidade estudada, é "normal que os especialistas do parto inventem ritos para acompanhar seu ofício. Porém, esses ritos não são universalmente eficazes. Têm uma significação para aqueles que os criaram; reforçam um sistema de valores ligado à família moderna: intimidade, igualdade entre os esposos, a importância central do vínculo mãe/ filho, e a imagem da criança enquanto ser psicologicamente em formação. Um "lindo parto" seria a condensação em um só retrato desses valores". Considerar que a boliviana "quer o parto normal" porque os bolivianos "sabem que aquele momento do stress do pré-parto ele vai passar assim que nascer" é um valor da entrevistada.

Uma outra entrevistada, a enfermeira Marta, quando indagada se considera que o hospital está preparado para receber estrangeiras, respondeu que "não tem problema, porque o parto é diferente de uma cirurgia, cirurgia em si, que você precisa dar uma atenção e explicar, orientar, pra ela entender, o parto é parto, ela sabe que veio aqui pra ter nenê", o que nos parece indicar não apenas a dificuldade na percepção das diferenças culturais quando do atendimento de mulheres estrangeiras, como também a redução do parto a um evento fisiológico, igual para todas as mulheres.

Essa perspectiva biológica é construída na formação do profissional (Camargo Júnior, 2003), que aprende a valorizar um sistema de crenças que sustenta essas práticas, menciona Fonseca (1992, p. 21) ao falar dos médicos, ressaltando o fato de que quanto "mais se estudou, maior a tendência a respeitar os preceitos e as descobertas da 'ciência'. [...] Os outros sistemas de saber, se não se mostram compatíveis com esta ciência, são relegados ao domínio das superstições, do folclore, ou talvez até mesmo das "crenças étnicas"”.

Orientada por essa objetividade, na fala da entrevistada, o parto, diferente de uma cirurgia, não precisa ser explicado; tampouco a parturiente precisa de orientação ou de maiores atenções, uma vez que ela sabe porque foi ao hospital, ou seja, "para ter nenê", desse modo, não precisa de explicações. Por contrapartida, também não precisaria ser compreendida, uma vez que se entende 
que "parto é parto", o foco da atenção passa a ser dado no plano biológico e nas intervenções biomédicas consideradas adequadas, as quais se fundam no disciplinamento e na normatização pelo hospital dos comportamentos dos sujeitos atendidos.

Foucault (1987, p. 164), em capítulo sobre a docilidade dos corpos, discorre sobre os métodos e operações de controle e sujeição dos corpos, dados no momento histórico das disciplinas. Esses métodos, minuciosamente calculados e aplicados, impõem ao sujeito "uma relação de docilidadeutilidade", de obediência. O hospital é um dos espaços centrais de docilização e disciplinamento dos corpos; local de normatização dos comportamentos, como exemplificam as referências às parturientes bolivianas pelos profissionais de saúde entrevistados na maternidade pública estudada.

Se, por um lado, no hospital, a perspectiva biológica do parto faz referência a algo que se acredita universal, orientando as normatizações, o evento sempre se inscreve num contexto sociocultural, que dita as regras que vão regular esse parto. Como observam estudos a esse respeito (Jordan, 1993; Gualda, 2002), essas regras, que regulam o parto e que são específicas a cada contexto cultural, vão determinar e especificar não só o local considerado mais apropriado para se ter o bebê, mas também as pessoas que deverão participar, assistir, bem como a forma de parir. Conforme esclarece Jordan (1993, p. 48) "A perspectiva localmente compartilhada de nascimento e parto garante que, de modo geral, os participantes do evento tenham ideias semelhantes em relação ao modo como deve transcorrer e como se deve manejá-lo."

Durante as entrevistas, situações e casos que parecem ter impactado a equipe foram relatados, sinalizando para a necessária consideração da cultura do outro, dos sentidos atribuídos a determinadas práticas, na relação de cuidado. A desconsideração ou incompreensão dessas práticas e suas intenções pode levar a equívocos mais ou menos graves e, acima de tudo, ao desrespeito. A entrevistada Diana traz uma ideia de uma situação em que esses equívocos e incompreensões são colocados:

Então, eu já cheguei aqui e uma boliviana entrou no sábado e ai lá no centro obstétrico ela queria [o parto] de pé, de pé, e ai ela pediu o cesto né, em espanhol. Pediu o cesto porque ela não queria que o bebê dela caísse, porque ninguém queria pegar o bebê dela e estavam forçando ela a deitar. Aí ela pediu o cesto, ela não pediu o lixo, ela pediu o cesto [risos], só que o pessoal falou assim "ela quer jogar o bebe no lixo”, ai uma médica que nós tínhamos falou assim 'não, você vai ter o bebê deitada', tentando lá se comunicar da forma como pode. Então pegou ela por traz, deitou a paciente lá na mesa, fizeram o parto deitada. Essa paciente, ela, nossa, ficou 
louca! Só que eles entenderam que ela queria jogar o bebê no lixo, não queria o bebê. . [...] Mas ela muito tranquila, falou 'eles não entenderam, agora que eu entendi que aquilo que eu pedia que era o cesto, era o lixo, só que eu não queria jogar o meu bebe no lixo' [...] Então isso é uma dificuldade, você tem que conhecer a cultura das suas pacientes [...].

Do observado e das entrevistas realizadas podemos considerar que, para os profissionais de saúde, e em função de determinados comportamentos das gestantes durante o trabalho de parto, como o acima exposto pela entrevistada Diana, é imprescindível considerar os sentidos culturais aí implicados, como ela diz "a cultura das suas pacientes". Para outros profissionais, no entanto, o parto é visto como um evento ou ato "apenas" fisiológico, sem que haja consideração dos aspectos emocional, social e cultural que o circunscreve. Cabe considerar que o parto hospitalar no Brasil é historicamente baseado em um modelo biomédico e muitos profissionais foram formados em tal modelo de assistência (Diniz, 2005). Baseado nessa compreensão, ainda que haja, por parte dos profissionais de saúde, um esforço de aproximação da cultura do "outro" e dos costumes e crenças próprias a ela, os elementos biológicos e normativos sobrepõem-se aos fatores sociais e culturais na explicação e abordagem dos fenômenos corporais, como o parto.

A hegemonia desse saber e das práticas a ele relacionadas, em relação ao parto hospitalar, evidenciam um processo de aculturação, dada a imposição de um modelo único, resultando no encobrimento das diferenças e no acirramento das tensões.

\section{Considerações finais}

O presente estudo buscou trazer elementos para uma melhor compreensão do tema atenção obstétrica para mulheres estrangeiras em um serviço público de saúde. Os dados das DNV indicaram que as mulheres estrangeiras compõem um grupo numericamente importante na maternidade estudada, o que levou a instituição a desenvolver algumas ações para melhorar o acolhimento, facilitar a comunicação e instrumentalizar os profissionais para lidar com o fenômeno. Entretanto, tratam-se de iniciativas institucionais sem amparo das políticas públicas, portanto, isoladas e pontuais, sem o alcance de um contínuo processo que possibilite um encontro de culturas, que assim se reconheçam e que no cotidiano do trabalho possibilite a flexibilização do modelo biomédico.

Estudos sobre a migração de mulheres (Dias et al., 2010) indicam que o número de migrantes tem aumentado, resultando em grande desafio para 
a área da saúde. Ao mesmo tempo, a maior ocorrência de partos normais entre as bolivianas é um dado que pode ser visto como favorável e demonstra que na interação face-a-face elas conseguem viabilizar a via de parto de preferência, apesar das grandes dificuldades de comunicação com a equipe de saúde, dada, em especial, pelo idioma, enquanto muitas brasileiras apesar de manifestar preferência pelo parto normal, têm como resultado a cesárea, como indica a pesquisa Nascer no Brasil (Domingues et al., 2014). Contudo, por sua formação centrada no modelo biomédico, alguns profissionais de saúde enfrentam dificuldades para a compreensão e consideração de elementos culturais no momento do parto como, por exemplo, a escolha pela posição vertical, que é solicitada principalmente pelas bolivianas. Há o predomínio de um modelo de atenção obstétrica prescritivo, que não considera os desejos e preferências das mulheres.

Do ponto de vista das possibilidades de políticas públicas de saúde, o fato de muitas mulheres possivelmente se encontrarem indocumentadas e em situação irregular no país, portanto, fora das estatísticas de contagem populacional, pode ser um dado explicativo para a quase ausência de ações que considerem as necessidades dessa população. De qualquer modo, as informações coletadas neste estudo indicam que no setor de saúde é possível acessar dados que estimem a população estrangeira usuária dos serviços públicos de saúde e informações que subsidiem a formulação de políticas públicas nos diferentes níveis de gestão do SUS. A necessidade de políticas públicas voltadas para o atendimento da saúde dessa população é sentida "na ponta" por muitos profissionais que atendem as mulheres estrangeiras e que usam da criatividade para buscarem superar a insuficiência do modelo biomédico no sentido de realizarem uma assistência mais adequada, que, de fato, considere o "outro" nas suas particularidades culturais, enfrentando, ao mesmo tempo, dificuldades e contradições próprias à focalização biomédica no orgânico.

O serviço de saúde é acessível às mulheres estrangeiras, quando da realização do parto, entretanto, as diferenças culturais e, especificamente, as diferenças culturais no parto, aliadas às desigualdades de classe, fazemse presentes, de modo dramático, no cotidiano de trabalho. Os relatos dos profissionais indicam que é necessário o desenvolvimento de ações que possibilitem refletir sobre a importância do respeito às diferenças culturais no parto, superando a consideração do mesmo como um evento apenas biológico. É certo que a complexidade da migração estrangeira se constitui em um grande desafio a ser enfrentado no desenvolvimento de ações que possam comportar as diferenças culturais e garantir a equidade na 
atenção à saúde. Especificamente na assistência obstétrica nos parece que urgem novos estudos, também com foco nas percepções das estrangeiras sobre as relações de cuidado, e iniciativas que levem a incorporação da dimensão cultural do parto nas políticas e práticas de saúde, com vistas ao desenvolvimento de ações que impliquem, de modo amplo, a atenção ao parto culturalmente adequado. No âmbito das políticas públicas, indicam que é necessário considerar o fenômeno migração internacional na formulação das políticas de saúde.

\section{Referências}

BAENINGER, Rosana. O Brasil na rota das migrações latino-americanas. In: Rosana Baeninger (Org.). Imigração boliviana no Brasil. Campinas: Núcleo de Estudos da População-Unicamp, 2012. p. 9-18.

CABRUJA, Teresa; IÑIGUEZ Lupicinio; VÁSQUEZ Félix. Cómo construimos el mundo: relativismo, espacios de relación y narratividad. Anàlisi. v. 25, p. 61-94, 2000.

CAMARGO Jr. Kenneth Rochel. Biomedicina, saber e ciência: uma abordagem crítica. São Paulo: Hucitec, 2003.

CAPONI, Sandra. Da compaixão à solidariedade: uma genealogia da assistência médica. Rio de Janeiro: Fiocruz, 2000.

COSTA, Jurandir Freire. Ordem médica e norma familiar. Rio de Janeiro: Graal, 1979.

DIAS, Sonia Ferreira; GAMA, Ana Filipa; ROCHA, Cristianne Maria Famer. Conhecimentos sobre o uso de contraceptivos e prevenção de DST: a percepção de mulheres imigrantes. Cadernos de Saúde Pública, v. 26, n. 5, p. 1003-1012, 2010.

DINIZ, Carmem Simone Grilo. Humanização da assistência ao parto no Brasil: os muitos sentidos de um movimento. Ciência e Saúde Coletiva, v. 3, n. 10, p. 627-637, 2005.

DOMINGUES, Rosa Maria Soares Madeira et al. Processo de decisão pelo tipo de parto no Brasil: da preferência inicial das mulheres à via de parto final. Cadernos de Saúde Pública, v. 30, suplemento, S101-S116, 2014.

FONSECA, Cláudia. Anatomia de uma maternidade: pesquisadores, profissionais de saúde e pacientes num quadro hospitalar \{Originalmente: 1992, Quelques réflexions ethnologiques sur une maternité française. Ethnos $\}<$ http://files.claudialwfonseca. webnode.com.br/200000057-604af61453/Anatomia\%20de\%20uma\%20maternidade, \%202010.pdf> (19 dez. 2014).

FOUCAULT, Michel. História da sexualidade: a vontade de saber 1. São Paulo: Edições Graal, 2006.

FOUCAULT, Michel. Vigiar e punir: nascimento da prisão. Petrópolis: Vozes, 1987.

FOUCAULT, Michel. Microfísica do poder. Rio de Janeiro: Graal, 1979.

GUALDA, Dulce Maria Rosa. Eu conheço minha natureza: a expressão cultural do parto. Curitiba: Editora Maio, 2002. 
ILLES, Paulo; TIMÓTEO, Gabrielle Louise Soares; FIORUCCI, Elaine da Silva. Tráfico de pessoas para fins de exploração do trabalho na cidade de São Paulo. Cadernos Pagu, v. 31, p. 199-217, 2008 <www.scielo.br/pdf/cpa/n31/n31a10.pdf> (7 ago. 2013).

JORDAN, Brigitte. Birth in four cultures: a crosscultural investigation of childbirth in Yucatan, Holland, Sweden and the United States. Long Grove, Waveland, Press, 1993.

MADI, M. C. C.; CASSANTI, A. C.; SILVEIRA C. Estudo das representações sociais sobre gestação em mulheres bolivianas no contexto da atenção básica em saúde na área central da cidade de São Paulo. Revista Saúde e Sociedade, v. 18, suplemento 2, p. 67-71, 2009.

OTIS, Kelsey E.; BRETT, John A. Barriers to hospital birth: why do many Bolivian women give birth at home? Revista Panamericana de Salud Pública, v. 24, n. 1, p. 43-53, 2008.

PREFEITURA de São Paulo. Coordenação de Epidemiologia e Informação. Atenção o pré-natal na cidade de São Paulo. Boletim CEInfo, v. 5, n. 1, 2014.

SILVA, Sydney A. da. Bolivianos em São Paulo: dinâmica cultural e processos identitários. In: Rosana Baeninger (Org.). Imigração boliviana no Brasil. Campinas: Núcleo de Estudos de População, 2012. p. 19-34.

SIMMEL, Georg. O estrangeiro. Revista Brasileira de Sociologia da Emoção, v. 4, n. 12, p. 265-271, 2005.

SOUCHAUD, Sylvain; BAENINGER, Rosana. Collas e cambas: do outro lado da fronteira: aspectos da distribuição diferenciada da imigração boliviana em Corumbá, Mato Grosso do Sul. Revista Brasileira de Estudos de População, v. 25, n. 2, p. 271-286, 2008.

SOUZA, João Paulo; PARPINELLI, Mary Angela; AMARAL, Eliana; CECATTI, Jose Guilherme. Assistência obstétrica e complicações graves na América Latina e Caribe: análise das informações obtidas a partir de critérios demográficos de saúde. Revista Panamericana de Salud Pública, v. 21, n. 6, p. 396-401, 2007.

SPINK, Mary Jane (Org.). Práticas discursivas e produção de sentidos no cotidiano. São Paulo: Cortez, 1999.

RODRÍGUEZ, Lilia. Factores sociales y culturales determinantes en salud: la cultura como una fuerza para incidir en cambios em politicas de salud sexual y reproductiva. In: III Congresso da Associação Latino Americana de População, ALAP, Córdoba, Argentina, $2008<$ http://www.ossyr.org.ar/pdf/bibliografia/2.6.pdf> (13 jun. 2015).

TORNIQUIST, Carmen Suzana. Paradoxos da Humanização em uma maternidade no Brasil. Cadernos de Saúde Pública, v. 19, sup. 2, p. S419-S427, 2003.

WALDMAN, Tatiana Chang. Movimentos migratórios sob a perspectiva do direito à saúde: imigrantes bolivianas em São Paulo. Revista de Direito Sanitário, v. 12, n. 1, p. $90-114,2011$.

Recebido em: 2 jun. 2014

Aprovado em: 12 jan. 2015

Autora correspondente:

Cláudia Medeiros de Castro

Av. Arlindo Bettio, 1000 - Ermelino Matarazzo

03828-000 - São Paulo, SP 